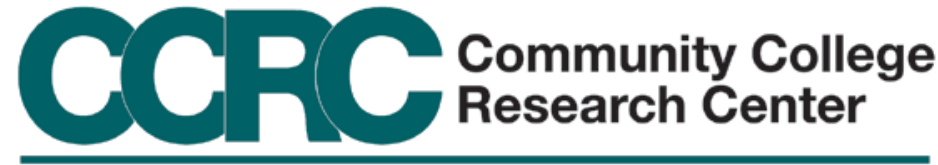 \\ TEACHERS COLLEGE, COLUMBIA UNIVERSITY
}

\section{“They Never Told Me What to Expect, so I Didn't Know What to Do": Defining and Clarifying the Role of a Community College Student}

\author{
Melinda Mechur Karp and Rachel Hare Bork
}

July 2012

CCRC Working Paper No. 47

Address correspondence to:

Melinda Mechur Karp

Senior Research Associate, Community College Research Center

Teachers College, Columbia University

525 West $120^{\text {th }}$ Street, Box 174

New York, NY 10027

212-678-3091

Email: mechur@tc.columbia.edu

Funding for this study was provided by the Bill \& Melinda Gates Foundation. The authors are grateful to Melissa Barragan, Susan Bickerstaff, Nikki Edgecombe, and Zawadi Rucks-Ahidiana for research assistance and feedback on earlier drafts. Shanna Jaggars also provided valuable feedback on previous drafts of this paper. 


\begin{abstract}
Increasing the number of young people who attain postsecondary credentials has become one of the primary educational objectives of the 2010s. While low college success rates are typically linked to students’ lack of academic preparation for college and their subsequent need for developmental or remedial instruction, research suggests that even many students who are deemed “college-ready” by virtue of their placement test scores or completion of developmental coursework still do not earn a credential.

This paper builds on previous work arguing that community college success is dependent not only upon academic preparation but also upon a host of important skills, attitudes, and behaviors that are often left unspoken. Drawing on role theory and on a qualitative study conducted at three community colleges, this paper aims to clarify the role of community college student and the components of that role that must be enacted for students to be successful. Using data from interviews at the study sites, we provide a concrete, actionable description of the community college student role. We also present a framework that practitioners can use to help students learn how to be successful community college students.
\end{abstract}




\section{Table of Contents}

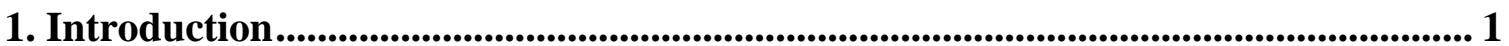

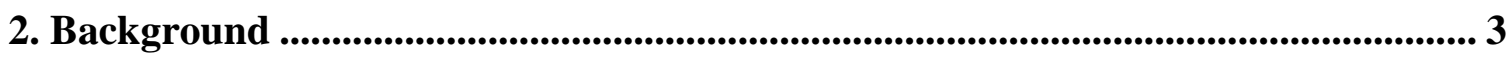

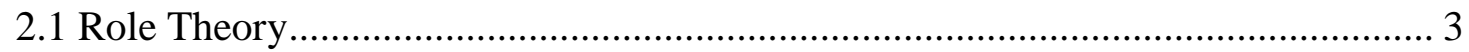

2.2 Poor Definition of the Community College Student Role ................................... 4

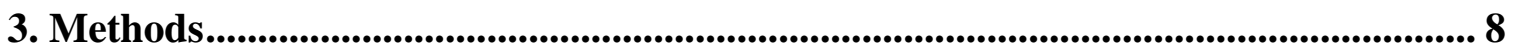

4. Findings................................................................................................................. 10

4.1 Fluidity and Awareness in the Community College Student Role ....................... 11

4.2 Four Specific Components of the Role .......................................................... 14

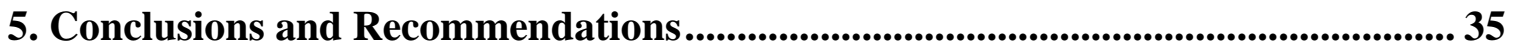

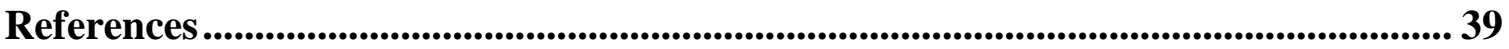





\section{Introduction}

Increasing the number of young people who attain postsecondary credentials has become one of the primary educational objectives of the 2010s (Bill \& Melinda Gates Foundation, n.d.; Lumina Foundation for Education, 2009; The White House, Office of the Press Secretary, 2009). In order to realize the nation's ambitious "achievement agenda," students need to not only find their way into college but also be successful once there. Only about 60 percent of first-time, full-time degree-seeking college students at four-year colleges actually earn a degree within six years, and only about 30 percent of first-time, full-time students at two-year colleges earn a certificate or associate degree within three years or within 150 percent of the normal time required to complete such credentials (Aud et al., 2012). Rates of degree completion are particularly low for nontraditional, minority, and economically disadvantaged students (Choy, 2002; Provasnik \& Planty, 2008; Aud et al., 2012).

Low college success rates are typically linked to students' lack of academic preparation for college and their subsequent need for developmental or remedial instruction (Bailey, Jeong, \& Cho, 2010; Jenkins, Jaggars, Roksa, Zeidenberg, \& Cho, 2009). However, research suggests that even many students who are deemed "college ready" by virtue of their placement test scores or completion of developmental coursework still do not earn a credential (Jenkins et al., 2009). The fact that even academically proficient students have trouble continuing in college suggests that college readiness encompasses more than just academic skills.

In this paper, we build on previous work arguing that community college success ${ }^{1}$ is not only about academic preparation but is also dependent upon a host of equally important skills, attitudes, habits, and behaviors (cf., Attinasi, 1989; Karp, 2011; Rosenbaum, Deil-Amen, \& Person, 2006). Community college students are held to certain behavioral standards—often unspoken and unwritten—by their professors and peers. Successfully meeting the expectations associated with these standards by

\footnotetext{
${ }^{1}$ The data upon which this paper is based are from community colleges, so we limit our discussion to this type of institution. However, it is reasonable to suggest that this paper's conclusions are applicable to students in four-year institutions as well, particularly students who are attending commuter or open-access four-year institutions.
} 
demonstrating appropriate skills and attitudes are fundamental to student success. Potential and new community college students are often unaware of these expectations, nor do they recognize their import for academic success (Venezia, Kirst, \& Antonio, 2003). In large part, this is because these expectations are not made clear to students. The mismatch between faculty expectations and student knowledge about those expectations disadvantages students and contributes to their low success rates.

We contend that this lack of clarity is unfair to students and is detrimental to the nation's goal of increasing postsecondary attainment. How can students live up to behavioral expectations that they do not know exist? Moreover, such lack of transparency is particularly detrimental to students from families that do not have college-going backgrounds. These students are less likely to be in contact with knowledgeable adults who can help guide them toward normatively appropriate college behavior, and they are less likely to possess the cultural repertoires that could help them understand the "unwritten rules" of the community college. Practitioners need to more clearly articulate their expectations for students so that students are provided guideposts for performing the nonacademic tasks and activities of collegiate life appropriately and successfully. To do this, practitioners and policymakers must first come to consensus about what, exactly, they expect of community college students.

The goal of this paper, then, is to articulate the largely unspoken behaviors, attitudes, and expectations to which students must adhere if they are to be successful. Drawing on sociological theory and on a qualitative study conducted at three community colleges, we aim to provide a clear definition of the role of community college student and a better understanding of what is expected of those who enter such a role. We also provide distinct strategies that can be used by community college students to meet these expectations. Using data from interviews at three community colleges, we provide a concrete, actionable description of the community college student role. As a result, we not only clarify a piece of the college success puzzle that has heretofore been underexamined, but we also set forth a framework that practitioners can use to help students learn how to be successful community college students. 


\section{Background}

This section provides a framework for understanding the role of the community college student. We examine the literature surrounding the expectations of college students, including the sociological concept of roles and role-related behaviors. This section also introduces a set of terms and concepts that are used to frame the findings presented in the remainder of the paper.

\subsection{Role Theory}

We base our contention that students need to better understand the non-academic expectations of college in sociological theory of roles and role change. Role theory purports that people play roles, or parts, throughout their lives (Goffman, 1961; Blumer, 1969; Turner, 1990). Each role—parent, spouse, student, worker, friend—has a comprehensive set of behaviors, attitudes, values, and ways of interacting that other people expect from those who enact these roles (Turner, 1990).

Roles are fundamentally social in that we as a society work together (albeit in typically unspoken ways) to define what is and is not acceptable from individuals in a given role. People act in ways that are in accordance with the socially understood behaviors of the roles they assume (Blumer, 1969); if they do not comply, they are likely to receive negative feedback from others. Take, for example, a new driver. We-others in society — expect that this individual will obtain a license, drive carefully, responsibly and on the correct side of the road, and obey all traffic rules. If the new driver does not do this, she will be sanctioned, through traffic fines and, possibly, the revocation of her license.

Behaviors and attitudes that are linked to the definitions and expectations of a specific role are called role-related behaviors. The role of motherhood, for example, is characterized by nurturing behaviors directed toward one's children. Those who inhabit a specific role are referred to as role incumbents and those with whom they interact are called role alters or role others. Role others for a mother, for example, may include a father and children.

As individuals move through life, they take on new roles and must learn to enact appropriate role-related behaviors and attitudes. Enacting these new behaviors is a signal 
to others that a person has taken on a new role. For instance, demonstrating responsibility for one's financial health by paying bills on time and behaving independently by getting one's own apartment can signal that a young person has taken on a new role as an adult. Importantly, because not learning how to enact a new role leads to negative feedback, a key element of entering a new role is learning how to play the part appropriately.

How do people learn the expectations of new roles? Sociologists have identified a process of socialization, whereby those already in a given role or who are familiar with it teach potential entrants the normative attitudes and behaviors related to that role (Merton, 1957; Simpson, 1979; Ebaugh, 1988; Olesen \& Whittaker, 1968). Socialization can occur within formal organizations, such as a professional school or apprenticeship, or more informally, such as when parents teach young people how to behave appropriately. Throughout this process, individuals learn about three key aspects of a given role: its technical demands, such as the actual skill entailed in doing a job; its normative expectations, including habits and values of successful role incumbents; and its desirability, which provides motivation to enter the role.

\subsection{Poor Definition of the Community College Student Role}

The above description of roles and role-related learning is accurate for many social positions, but it assumes that all roles are clearly defined. ${ }^{2}$ But what happens when the confines of acceptable role-related behaviors are not clear-cut? Some roles are less well defined than others, and it is much harder for new entrants to learn to "play the part" in these situations (Ibarra, 1999).

In many respects, the normative expectations of the role of college studentparticularly those of community college student—are ill defined (Collier \& Morgan, 2008). Efforts to improve the alignment of high school and college academics have gone a long way toward generating a clear set of technical or academic demands of the college student role, and increased awareness of the need for post-high school education for success in today’s workforce has helped to motivate individuals to enter the role. Yet,

\footnotetext{
${ }^{2}$ It should also be noted that roles and role-related behaviors are ideal types. Individuals do not adhere to every aspect of a role's definition in every situation, though as noted, if they veer too far from the expected behaviors they will be sanctioned.
} 
although a generalized set of expected student behaviors exists, how these change as one moves from high school to college is not well articulated. Moreover, specific expectations likely vary between institutional types, as well as between colleges of the same type, or even among different disciplines or specific faculty members.

Interviews with high school students indicate that potential community college students have little understanding of what will be expected of them in terms of their behaviors and attitudes once they enter college (Karp, 2006; Venezia et al., 2003; Venezia, Bracco, \& Nodine, 2010). In addition, interviews with college students reveal that students enter postsecondary education with a vague sense that college is different from high school, but without awareness of the specific ways in which it is different (Collier \& Morgan, 2008; Cox, 2009). The mismatch between expectations and students' understandings is particularly pronounced among first-generation college students (Collier \& Morgan, 2008).

Conceivably, potential community college students could learn about the expectations of the role from high school teachers and counselors. But a range of research has shown that this is not the case: high school staff often do not know about or understand the community college student role and cannot or do not communicate it to their students. Venezia et al. (2010) found that while community colleges almost universally claim to participate in outreach to neighborhood high schools, students feel that they are given little information prior to enrollment. Rosenbaum, Stephan, and Rosenbaum (2010) illustrate the confusion held by those we might expect to be in a position to help:

Counselors often say that students can enter college even with low achievement in high school, but they rarely warn that low-achieving students cannot enter college-credit classes or certain programs. Avoiding these details keeps students optimistic and encourages their college plans. However, it also gives students insufficient information to make sound decisions. (p. 5)

Moreover, many community college students do not enroll in college directly after high school, making any information provided via this route available to only a subset of the community college student population. 
Popular images of college might be another source of information, but they too provide little guidance to potential community college students. Many portrayals of college on television, for example, such as on Greek or Gossip Girl, take place at residential four-year institutions and focus on the social aspects of college rather than on academic coursework. Even the rare show set on a community college campus is minimally helpful: While the NBC sitcom Community portrays the intergenerational relationships that can be fostered on a community college campus, it focuses on the hijinks of the group and not on their academic pursuits. Certainly, it is not the intention of Community or any other popular entertainment to provide students with a realistic image of college, but for students without any other college-going landmarks, it may be all they know.

News outlets also paint an inaccurate picture of what college is really like for millions of students. The New York Times, for example, in its "Education Life" section, defines college as a four-year, residential experience and rarely refers to other forms of postsecondary education. The prevalence of these images both reinforces the notion that college is a homogenous institution and provides little information for the many students attending two-year and commuter institutions.

Though potential and new community college students may not be explicitly told about the expectations to which they will be held, the faculty who await them on campus certainly hold such expectations. Researchers such as Collier and Morgan (2008), Attinasi (1989), Shields (2002), and Dickie and Farrell (1991) found that new college students must learn to navigate a complex system of bureaucratic requirements, learn new study habits and time management strategies, and engage in new kinds of social relationships, among other things. Students who do not have this knowledge—often referred to as college readiness skills—are unlikely to be successful in college, even if they have the required academic skills.

Although recent research has attempted to clarify the non-academic knowledge, skills, and behaviors necessary for college success (see, for example, Conley, 2005; 2007a; 2007b; 2010; Roderick, Nagaoka, \& Coca, 2009; Collier \& Morgan, 2008; Byrd \& MacDonald, 2005), the existing body of work on this topic has two drawbacks. First, it provides little concrete guidance for community college students who are seeking to 
understand, or community college faculty who are seeking to communicate, the expectations to which students are held. For example, Byrd and MacDonald (2005) defined the role of the college student by noting that successful community college students have strong time-management skills and goal-orientation, can advocate for themselves in order to get help, and understand college systems and procedures. They did not, however, provide clear strategies for enacting these expectations. What specific timemanagement skills do successful community college student possess, and how are those skills different from the ones required of high school students?

Second, much of the work is not necessarily applicable to the particularities of today's community college student (Conley, 2005; Roderick et al., 2009; Roderick, Nagaoka, Coca, \& Moeller, 2008; Collier \& Morgan, 2008). Conley, for example, assumes that most students will attend residential institutions, stating,

The great majority of [potential college students] hold the rather unsophisticated view that college is some sort of extension of high school, albeit without the same restrictive rules. They are naturally concerned about roommates, dorm food, and the like, but few have really digested what it is that college is going to do to them or expect from them. (Conley, 2005, pp. 117-118)

Such assumptions neglect the many students who live at home while attending college, not to mention adult students for whom high school is in the distant past and is not something to be extended into college. The college preparation literature also tends to focus on preparation for liberal arts programs (Conley, 2007a; Collier \& Morgan, 2008) and assumes that college readiness comes after completion of developmental education (Byrd \& Macdonald, 2005; Conley, 2007b)—neglecting the many students whose first encounter with postsecondary education occurs within the context of developmental coursework, as well as those students who are pursuing career and technical or terminal associate degrees.

The non-specific conceptualization of the role of community college student creates challenges for individuals seeking to enter that role. Those who do not learn the unwritten rules of a social role are more likely to receive negative feedback, to be unsuccessful, and ultimately to leave the role. For community college students, this 
means that a lack of clarity about what is expected of them and how to achieve those expectations is likely to lead to negative feedback in the form of poor grades or discomfort on campus, and —in many cases_college dropout. Interviews with high school students indicate that the lack of understanding of normative expectations contributes to low levels of college success (Venezia et al., 2003; Venezia et al., 2010). Students who are unfamiliar with college, who fear failure, or who are tenuously connected to higher education are particularly likely to struggle in college as a result of unclear expectations (Cox, 2009; Collier \& Morgan, 2008).

The bottom line is that, without clear guideposts helping students to understand what is expected of them in community college, student success is inhibited. Only if the expectations are clearly defined, in actionable and meaningful ways, can students live up to them. The remainder of this paper attempts to provide a data-based conception of the community college student role. We articulate the various behaviors and attitudes that college faculty and staff expect community college students to demonstrate. Moreover, we provide specific strategies used by college students to meet those expectations. The goal is to provide practitioners with a way to frame a conversation about college readiness that goes beyond academic skills, providing them with specific details that can be clearly communicated to potential and new community college students so as to put them on a more certain path to postsecondary success.

\section{Methods}

This study uses qualitative data from semi-structured interviews conducted in 2010 with community college students $(n=96)$ and faculty and staff $(n=72)$ for a study of student success courses at three colleges in the Virginia Community College System. ${ }^{3}$ Of the faculty and staff, 46 percent had taught a student success course, with the remainder consisting of administrators, student services staff, and other academic

\footnotetext{
${ }^{3}$ For more information on the larger study, see the forthcoming CCRC paper, College 101 Courses for Application and Student Success (Karp et al., 2012).
} 
faculty. ${ }^{4}$ The students interviewed were predominately attending college full time (75 percent), although many were also working. Overall, 55 percent of the students were women, 67 percent were White, and slightly more than half ( 55 percent) were between 18 and 20 years old. At the time of the interview, each student interviewee was currently enrolled in or had recently completed a student success course; the course provided students with an orientation to college, including guidance on skills and student services useful for achieving college success. In Virginia, these courses are required for graduation, and colleges encourage students to take them in their first semester (Cho \& Karp, 2012); therefore, our sample population is relatively representative of the larger set of incoming and new students in these community colleges.

Interviews focused on student success course implementation, campus contexts, instructional expectations, and student experiences during the transition to college. Our analysis draws on a subset of questions included in the interview protocols about expectations of students, expectations of the institution, and student needs. All interviews are included in this analysis.

Data were analyzed using NVivo qualitative analysis software. The research team developed a detailed set of codes to analyze each transcript for a range of "big bucket" topics related to the overall research questions of the larger study. Coding validity was ensured through a series of validity checks, where every 10th transcript was coded by multiple researchers. The research team also met weekly to discuss discrepancies in the coding, challenging passages, and areas of the coding scheme in need of refinement.

Upon completing the big-bucket coding, the research team identified the nodes "expectations of students" and "student needs" as potentially useful for further exploration to aid in understanding the role of a community college student. We examined these data thematically, in the tradition of analytic induction (Le Compte \& Preissle, 1993; Ragin, 1994). Through our close reading and re-reading of the data, we sought to categorize disparate expectations into manageable and actionable chunks.

\footnotetext{
${ }^{4}$ Given the nature of staffing student success courses in Virginia, many student success course instructors also served in other professional capacities. The forthcoming CCRC report, College 101 Courses for Application and Student Success (Karp et al., 2012) goes into more detail regarding the staffing configurations of these courses.
} 
During the analytic process, we created matrices outlining the various categories that emerged from the data. We also used a "memoing” process (Bernard, 2002) to describe and clarify our proposed model of the role of community college student. We discussed the matrices and memos with the research team, refining them until they best represented the data in the dataset. Throughout the analysis process, our goal was to clarify the role of a community college student and identify strategies used by students to enact that role.

\section{Findings}

What are the expectations to which community college students are held? Our data indicate that the community college student role is fundamentally different from the non-college roles that community college students often play in two important ways. These differences cut across a range of community college student expectations and consequently make the role challenging for new students to enact. First, community college students are expected to be self-aware, assessing their progress and needs in largely unaccustomed ways. Second, the community college student role is more fluid than other roles, in that there are more strategies that might lead to successful role enactment.

Our data also reveal four specific areas of knowledge and behavior that make up the community college student role. We call these the four components of the role. Community college students are expected to engage in new academic habits or approaches to school-related activities that support their academic success. They must exhibit cultural know-how in order to understand and adhere to unwritten institutional norms. Next, students must balance the multiple roles that they may play in their life. Finally, community college students are expected to engage in self-directed and timely help-seeking behavior. Together, these four components represent the core elements of the role of the community college student. The remainder of this section reviews the community college role in more detail. 


\subsection{Fluidity and Awareness in the Community College Student Role}

In two important and cross-cutting ways, the community college role is characterized by new forms of thinking and new strategies for enactment, particularly when compared with other roles with which students are often familiar. First, respondents noted that the community college student role was more fluid than other roles-meaning that the role was less structured, more flexible, and included fewer forms of clear feedback than other roles. Second, and largely due to the fluidity of the role, community college students must exhibit high degrees of reflection, such that they can cognitively evaluate their actions in order to modify them if necessary in order to meet the expectations of the community college student role. The newness of the community college role is therefore particularly problematic, because students have fewer frames of references or experiences to draw upon, and they cannot rely on their knowledge of other roles for guidance.

The fluidity of the community college student role is most evident when comparing the role to others with which students are often familiar. These comparisons are illustrated in Table 1. Analyses of interviews revealed "fluidity" to be made up of three composite parts or dimensions: structure, feedback, and variability. The first dimension, structure, relates to how clearly defined and prescribed the role is. For example, high school students are typically given a course schedule, whereas community college students must create their own schedules and select among multiple sections (and even instructors) for any given course they want to take. High school students must adhere to a strict schedule that dictates when they engage in academics and when they take breaks, while community college students have no such constraints on their time. One student explained,

When you're coming straight out of high school, you have somebody telling you what to do and how to do it and when to do it. And then you get to college. ... When I went the first time, they never told me anything to expect so I didn't know what to do.

The second dimension of role fluidity, feedback, relates to how often role incumbents are told by others whether or not they are meeting expectations. Employees 
typically have clearly defined tasks to complete and are likely to get immediate feedback on their performance. In contrast, a common refrain among the community college students we spoke with was the infrequency of assignments and of subsequent opportunities for feedback from professors on their academic progress. Instructors emphasized that if students wanted regular feedback, they must seek it out, as it is not automatically given, and they also emphasized that community college students are expected to develop their own sense of whether or not they are making progress toward their academic goals. One instructor alluded to the lack of explicit feedback received by community college students when describing the way that students need to —on their own—examine their work: "[A student should] look at what [he] missed and why [he] missed it ... [and a student should consider,] if I didn’t do too well, what do I need to do differently?”

Finally, as compared with other roles, the community college student role is highly variable, in that there are many ways to meet a given role-related expectation. For example, community college students are expected to pass exams with little guidance or instruction on how to study - they can achieve a passing grade using any number of strategies, including flash cards, rewriting their notes, or reading the text multiple times. Instructors frequently emphasized that a key element leading to success in the community college is students' ability to figure out "their own learning style, how they study best," implying that there is no one right way to study. High school students, in contrast, are often given discrete study-related tasks, such as creating flash cards for a vocabulary quiz or a timeline for a history test. Employees are also given concrete guidelines for their tasks.

Taken together, these three dimensions indicate how rigid or fluid role-related expectations are for a given social location. As compared with other roles, the community college student role leaves more room for individual interpretation and action, even when students must adhere to socially defined and understood standards of behavior. Students still must meet those expectations, but how they get there (course schedule, study approach, and so forth) is left to them to a greater extent than in other roles. 
Table 1: Fluidity of Various Roles

\begin{tabular}{llll}
\hline & High school student & Employee & Community College student \\
\hline Structure & $\begin{array}{l}\text { High } \\
\text { daily homework }\end{array}$ & $\begin{array}{l}\text { Clear } \\
\text { discrete job tasks }\end{array}$ & $\begin{array}{l}\text { Little } \\
\text { student-designed schedule and time } \\
\text { management }\end{array}$ \\
Feedback & $\begin{array}{l}\text { Frequent } \\
\text { unit tests }\end{array}$ & Frequent & Sporadic \\
& supervisor feedback & few graded assessments \\
Variability & $\begin{array}{l}\text { Minimal } \\
\text { discrete assignments }\end{array}$ & Minimal & High \\
& specific approaches to & independent study \\
\end{tabular}

Such fluidity then raises the question: How does one figure out how to enact a role that has less structure and clarity than one is used to? While the flexibility of the community college student role can be beneficial for students who know how to take advantage of it (we discuss this later), it does present additional challenges for those who are just learning to enact the role. Determining what strategies to use and when to use them appropriately requires a degree of reflection that is not necessary for the other roles with which community college students tend to be familiar. Community college students in our dataset were expected to assess their performance and diagnose potential solutions to role-related problems to a degree not seen in other roles. Without this second overarching characteristic — which we call self-awareness - community college students were unable to enact the four main components of the role.

We define self-awareness as an individual's ability to critically examine and reflect upon personal strengths and weaknesses in order to develop a plan for addressing self-diagnosed deficits as a means to successfully enact the role; the academic literature sometimes refers to this process as metacognition (Davidson, Deuser, \& Sternberg, 1994; Duckworth, Akerman, MacGregor, Salter, \& Vorhaus, 2009, Flavell, 1979). Some researchers have noted that the ability to understand one's own needs encourages academic success by developing an internal "feedback loop" in which students are able to monitor their own learning and anticipate, assess, and solve problems as they occur (Zimmerman, 1990, 2001; Carver \& Scheier, 1981; Zimmerman, Moylan, Hudesman, White, \& Flugman, 2011). 
Our data suggest the need for students to develop the ability to reflect upon and become aware of not only their academic learning but of their behavior as well. Enacting a fluid role requires students to examine their own adherence to role-related norms and to diagnose potential problems. One student, for example, described her reflection on her new, looser schedule and its implications for her study habits, saying, “And I've figured out that even though I have all that freedom, I'm still able to focus my time and efforts toward school work-not just, oh, I got a week to do that.” Another described his thought process in similar terms: “And now it's like, I got one class and then I'm done for the whole day. So it's like, what am I supposed to do?” Both of these students found that they had to think and reflect upon their behaviors in order to make sure that they were able to meet academic and other role-related demands.

Below, we provide additional examples of how the need for self-awareness influences aspects of the community college student role. It is important to recognize that the need for self-awareness is a highly prominent characteristic of the community college student role, and one that is likely new for many students. Moreover, it, like the notion of fluidity discussed above, contrasts with the expectations of many other roles with which community college students are familiar. Therefore, it is worth paying close attention to the ways in which new community college students develop self-awareness and the ramifications for their academic progress when they do not.

\subsection{Four Specific Components of the Role}

The remainder of Section 4 of this paper describes and analyzes the four components of the community college role: academic habits, cultural know-how, balancing multiple roles and time constraints, and help-seeking. As noted, we analyzed the data thematically and identified four broad "buckets" of knowledge, skill, and attitude required of successful community college students. These buckets make up four components of the college student role-items that others expect community college students to be able to know and to do. When students engage in these behaviors, they signal to others that they are serious about being a successful community college student. The subsequent sections discuss each of the four specific components in more detail. 
Academic habits. Our data indicate that the community college student role requires a revision of students' academic habits and behaviors. Recall that we are not discussing technical demands of the role, acquiring academic skills such as those needed for writing essays or factoring a polynomial. Instead, this component of the role refers to the normative behaviors and actions that contribute to academic success. Academic habits refers to activities that cut across disciplines and that generally entail new ways of going about or approaching school-related learning. These habits include strategies for completing college work, approaches to learning, and other academically oriented behaviors.

New community college students have experience with academic habits, of course, as they were all high school students at some point. But the community college role requires a change in these habits. Successful college student role enactment entails academic habits that are more independent, reflective, and self-initiated than are other student roles. The academic habits and behaviors we identified from our data are expected by college professors but differ in important ways from those expected by high school teachers. They require a new toolkit of strategies in order to successfully enact them. Table 2 summarizes these habits and behaviors, and provides sample strategies used by the students in our sample.

Table 2: Academic Habits

\begin{tabular}{|c|c|}
\hline Behaviors and attitudes & Strategies \\
\hline Manage workflow independently & $\begin{array}{l}\text { - Use a syllabus } \\
\text { - Complete work without clear due dates or that must be } \\
\text { done over a long period of time in increments }\end{array}$ \\
\hline $\begin{array}{l}\text { Organize and manage time and time-related } \\
\text { demands }\end{array}$ & $\begin{array}{l}\text { - } \quad \text { Find the best time and place to study for individual } \\
\text { circumstances } \\
\text { - } \quad \text { Plan ahead in order to carve out enough time to complete } \\
\text { assignments } \\
\text { - Study in new ways, and identify which methods work best }\end{array}$ \\
\hline Independent and reflective note-taking & $\begin{array}{l}\text { - } \quad \text { Take notes from multiple sources } \\
\text { - } \quad \text { Discern what is likely to be important }\end{array}$ \\
\hline Use the "tools of the trade" & $\begin{array}{l}\text { - Use tools and resources such as Blackboard and the } \\
\text { library appropriately } \\
\text { - Regularly access tools, even in the absence of explicit } \\
\text { instructions to do so }\end{array}$ \\
\hline
\end{tabular}


Manage workflow and time-related demands independently. Community college students are expected to manage their workflow independently. Unlike in high school, where students are given specific assignments to complete every day or specific studying tasks, community college students are expected to complete work on their own and in the manner that suits them best. The most prominent example of this expectation is the college syllabus, where students are given their expected work for the semester at the outset and then are left alone to complete it independently. Instructors do not regularly remind students to use the syllabus or to complete the reading assignments, and instead assume that students know to refer to it throughout the semester.

Independently completing work means that students must become less reliant on external supports or structures and more reliant on their own sense of discipline, sense of responsibility, and awareness of what is expected of them. They must learn to approach academic work in new ways - studying over long periods of time and thinking in more critical terms about what it means to successfully learn and master course requirements. One student described this new workflow by saying, "There's really no actual work. It's up to us to do the studying and the note-taking and stuff."

What is frequently referred to as new time management techniques is really a way to balance the role-related demands of independent academic habits. Students must effectively manage their time by learning new strategies for completing academic work. This is more than just creating a schedule for studying or finding ways to balance competing demands. Instead, it is the development of recognition that college work is different and therefore must be approached in a new way. For example, community college students are required to read and do work on their own, even when instructors do not explicitly review the assignment or collect it for a grade. As one instructor said, "You have to decide if you're going to study or not." The result is that students need to find the time to do this studying - but the role-related expectation is the completing of independent work, not time-management per se. ${ }^{5}$

Similarly, the pace of college courses requires new academic approaches. As noted above, courses have a few graded assessments or assignments each semester, with

\footnotetext{
${ }^{5}$ Cox (2009) argues convincingly that this expectation runs counter to student expectations and preferences, as students do not view college work as "real" or meaningful unless it is collected and graded.
} 
ungraded work to be completed in between. Learning to approach these graded assignments, which cover more material and are worth a larger component of the course grade than high school assignments, typically requires a new strategy. Part of the strategy is time management, but such management is really only an end toward students' learning to learn more on their own. Students are expected to think analytically in their work—rather than simply rush through it—and to start studying earlier in order to complete large assignments in a thoughtful and measured manner.

Interviewees summed up the need to develop new ways of managing time to promote independent, longer term learning throughout their interviews:

It's tough because you have to do so much and you have to remember so much. One class gave you 10 assignments, another class gives you 10 assignments, and it's kind of hard to do everything in one week. (Student)

...The freedom of time to just, you know, the freedom of assignments. Where it goes, you know, we need this threepage paper by next Thursday. Boom! Done! Last time you heard about it was, you know, the Tuesday before, and I can sit down with my planner and go, okay, Monday is this. Tuesday is this. Wednesday I'll do the outline for it. And it's just, it's so nice to be able to run my own ship, I guess. (Student)

Note that while these interviewees are discussing time management, they are at the same time describing the ways in which the community college role requires the development of new academic habits, such as studying during one's free time or using a planner, that encourage independent learning and can help students adapt to the new workflow of the collegiate environment. Likewise, these strategies require a degree of reflection in order to be effective. Students need to understand what is expected of them and how they can best achieve those expectations. They engage in self-regulated learning in order to recognize where they stand in their learning and where their weaknesses arewhat they need to work on.

Engage in independent and reflective note-taking. A second type of academic habit required by the community college student role is that of independent and reflective note-taking. Though high school students are also expected to take notes in class, college 
note-taking is fundamentally different. A student contrasted the two by saying, "Most of my history classes in high school would be, they gave us notes, like fill-in-the blank or something. But the lectures in college, they don't give you anything. You have to take all the notes yourself.”

As this student implied, community college students are expected to do more than copy what their instructor writes on the board. They must discern on their own which elements of a lecture or discussion are worth writing down. Successful community college students also discover that notes can come from multiple sources, including lectures, class discussion, and textbooks. To do this, they need to develop a more active and engaged approach to note-taking. As such, successful community college students are expected to actively construct their knowledge while simultaneously evaluating what is important and what they might have difficulty with.

One instructor described those students who do not successfully enact role expectations this way:

When I see students taking notes in a math class, invariably they write only what is on the board. Invariably they ignore what the teacher is actually saying, which is why this step is next. They just copy down, okay, "cross multiply.” [If one asks,] "Why do you cross multiply?" [they say] "I don’t know, she just did.”

Similarly, another instructor expects students to use their notes when studying. The instructor expected students to think about how they can "rewrite [their] notes, reconstruct [their] notes” in order to promote further learning. In sum, community college instructors want students to take notes on the course content in order to reconstruct the lesson later on, if needed.

Self-awareness is a key aspect of college note-taking habits. In order to be active note-takers, students must be able to think about what they might need to refer to in the future. They need to be able to reflect on what they know and what they are likely to need to know. Role others - particularly professors - expect students to develop an understanding of what is important without having to be told this explicitly. 
Use tools of the trade. Finally, community college students are expected to learn about and make a habit of using the "tools of the trade.” These include institutional tools (e.g., advising courseware or course registration systems), college support services (e.g., tutoring, course tools, including Blackboard or other course management systems, and basic technological applications), research tools (e.g., library and online resources); and interpersonal resources, (e.g., faculty or support staff). Interviewees indicated that college students are expected to make use of these resources independently and appropriately.

Unlike in other student roles, such as that of high school student, role alters for the community college student role do not remind students to make use of these tools. For example, students are expected to use the library on their own as appropriate for course assignments without having to be told to do so explicitly. They also need to access courseware, such as Blackboard or Moodle, regularly and on their own: “I’m assuming they know how to navigate Blackboard and send an email,” said one instructor. Moreover, the expectation is that students will use these resources correctly-for example, relying on online sources for research without resorting to plagiarism.

As with note-taking, using the tools of the trade effectively and appropriately also requires student reflection and self-awareness. Those individuals successfully enacting the community college student role must understand when to use a given resource as well as how to access the resource. One instructor described the reflective process by which successful community college students learn to use their syllabi appropriately:

It's there, the opportunity for [the students] to see the syllabus in the very beginning [of each course]. ... Most of them don't believe it. Then the first test comes and there is panic mode and then they want somebody to help them. And then they backtrack and try to fill in what they should have been doing from the very beginning.

In sum, the first component of the community college student role requires individuals to refine their academic habits to meet new expectations. These habits can be met via a variety of strategies, given the fluidity of the role. However, figuring out which academic habits and strategies are appropriate to use and when to use them requires selfawareness. Students must be able to reflect on their learning and their needs to identify behaviors that will benefit them and use strategies that are effective for their personal 
circumstances and learning styles. Role alters expect that community college students will independently take the time to think critically and analytically about both course content and their own understanding of that content in order to identify strategies, tools, and behaviors that will allow them to meet deadlines and complete assignments thoughtfully and effectively.

Cultural know-how. The second component of the community college student role is the development and use of cultural know-how. All institutions, community colleges included, have their own cultures and norms. A key element to successfully enacting the community college student role is that students must understand and adhere to institutional norms. Community college students are expected to have the contextual awareness to understand what is expected of them in given situations, and to determine how to adapt and conform to those expectations. We refer to this contextual awareness as cultural know-how in order to signify that students must understand the institutional culture and its importance, and know how to enact it.

It is important to note that college is rooted in White, middle-class culture (Rendon, Jalomo, \& Nora, 2000; Hurtado \& Carter, 1997; Tierney, 1999). The forms of discourse, types of language, and ways of interaction that are seen as "normal” or “accepted” tend to be rooted in middle-class norms, largely because college faculty have been educated in such cultures themselves. Though some have called for transforming these expectations via approaches such as culturally relevant pedagogy (Ladson-Billings, 1995; Paris, 2012), middle-class cultural expectations remain the norm in community college instruction. First-generation and minority students are particularly disadvantaged because they have less familiarity with these norms and know fewer individuals who can help them learn about them.

This is not to say that community college students need to "give up" their home cultures, but rather that in order to enact the community college student role effectively, they need to be able to adhere to institutional cultures, at least within the confines of the college environment. ${ }^{6}$ Not doing so will result in negative feedback from role alters as

\footnotetext{
${ }^{6}$ Whether the presence of a middle-class culture and culturally defined notions of motivation, effort, and commitment is appropriate is an issue worthy of discussion but is outside of the scope of this paper. We would certainly contend that such culturally constrained norms disadvantage certain groups of students and
} 
well as poor role performance-potentially culminating in poor academic outcomes (Collier \& Morgan, 2008). Community college students must, in effect, become what Lacy (2007) calls “code-switchers,” demonstrating their knowledge of middle-class norms even as they hold onto their home cultures. One instructor described this aspect of the role explicitly, saying that it is important for the college to figure out how to help students "make that cultural shift ... and sort of get them used to this academic culture and what we expect from them.”

Table 3 highlights the cultural know-how expected by interviewees, as well as strategies used by students to demonstrate such know-how.

Table 3: Exhibiting Cultural Know-How

\begin{tabular}{ll}
\hline \multicolumn{1}{c}{ Behaviors and attitudes } & \multicolumn{1}{c}{ Strategies } \\
\hline Engage in collegiate discourse & - Use academic and non-colloquial language in speaking and \\
writing
\end{tabular}

Engage in collegiate discourse. Faculty and administrator interviews revealed that community college students are expected to engage in "collegiate” forms of discourse. This includes using academic and non-colloquial language when both speaking and writing. An instructor explains: "Where do you draw the line at? That the textmessaging type of wording is not appropriate for college-level? ... [That] the lower case $i$ and these symbols are not college writing?” Another instructor noted that there are appropriate and inappropriate ways to interact with faculty members. Successful

that it is worth finding ways to make college success less dependent upon class-based normative understandings. However, our data indicate that these class-based expectations do exist and are in many ways reified; since our goal is to present a model of what community college students currently are expected to do, we take these norms and expectations at face value for the purposes of our conception of the role. 
community college students need to learn the difference, as well as to "[learn] how to feel comfortable [communicating] with a faculty member.”

Culturally acceptable discourse also includes the ability to engage in conversations about ideas and opinions rather than mere facts, as well as showing an openness to new ideas and experiences. One student told us that upon transitioning to college, "You need to be open to new opinions. I learned that." Note that this was new to him, demanded by the college environment, and different from other social roles he had held before. Another student told us that, in addition to time management and study skills, a key thing required for college success is open-mindedness: “Basically, just don't be closed-minded; be open-minded to a lot of things. To me being open-minded could be making new friends or getting different opinions about different things.”

Community college students are expected to participate in class discussions that are often free-wheeling and potentially controversial or uncomfortable. This requires verbal fluidity, as well as respect for new opinions, and recognition that this kind of “talk" is an academically and intellectually worthwhile endeavor. One student expressed frustration with a class that contained little lecture or discussion of the textbook, instead focusing on discussion and, in his mind, "rants.” He noted that "there were very strong opinions in the class," which took some getting used to, especially since he tended to be “a quiet guy in class.”

Demonstrate culturally defined forms of respect and commitment. Instructors also noted that the college student role requires demonstration of respect, commitment, and motivation in ways that are defined by middle-class norms and cultures. Instructors wanted to see that students really "wanted to be in college" but viewed only certain behaviors as indicative of such commitment and desire. Even students who felt that they were committed to obtaining a college degree were not viewed that way by instructors if they did not adhere to normative middle-class ideals of demonstrating respect for authority and motivation for collegiate-level learning.

Respect for authority and the collegiate enterprise was signaled by an array of student behaviors. Some of these were linguistic in nature, such as the desire for proper language use expressed by the instructor in the text-message language example above, whereas others involved personal appearance and self-presentation. One student told us 
that, upon entering community college, she learned that how she dressed influenced how her instructors viewed her: "You need to dress professionally when you are going to school because teachers will respect you more.”

One accepted form of showing commitment to college was to put forth a good faith effort both in and out of class. Instructors viewed such efforts as indicative of students' being goal-oriented and ready to put in the work necessary for college success. One instructor told us that for community college students, "mere attendance in the class is not sufficient to give you a passing grade. ...Y You're going to be expected to develop critical thinking skills ... not just a regurgitation of material to pass a standardized test.” Both faculty and students spoke of a give-and-take, whereby students who exhibit the appropriate form of "respect” for their instructors are more likely to receive help or positive reinforcement in return. A student explained:

If you go in their class and be disruptive and, you know, just aren’t very nice, then they're not going to be very nice to you, and they're not going to be lenient, especially if you turn in an assignment late.

Not exhibiting normatively accepted forms of commitment was often interpreted as being disrespectful or not being ready for college. Lamented one instructor:

Often [in high school] just showing up every day and breathing at the end of the semester guaranteed you a successful completion of a course. And now, they find that not only do I have to be here and stay alive, but I have to do something else and do it well and that's the part they really have difficulty with.

Another instructor expressed a similar sentiment when telling the following story:

Two weeks ago these two students, I believe they both have $\mathrm{D}$ [grades]. ... I know they are both extremely bright, and they're just not doing the work. And they both came up and said, "Oh we have to get at least Cs in this class, what do I have to do to get a C in the class." I said, "You can start by turning in your assignments." I said, in fact, "I'm going to give you until Friday. Put your assignments in my box ... I'll give you full credit for them." Neither one came to class today. At the end of the semester when they come to me and say, "But we really needed Cs," I'm not inclined at all 
to massage the numbers or whatever the case may be

because they're not living up to their end of the bargain.

Note her implicit expression of a give-and-take between teacher and student, a cultural expectation that leniency is something to be earned, not given, and that students who do not live up to their "end of the bargain” are not deserving of positive feedback.

Recognize that community college is less forgiving. The community college culture is less forgiving than other institutional environments, particularly high school, where exceptions are frequently made for students and their personal circumstances. Our data indicate that while some acknowledgement of personal circumstances was made, in general, community college students in the study were expected to function in a more impersonal and unforgiving environment than they were otherwise used to. This facet of the role was expressed by one instructor who said, “I just can't stop [a lesson] because a couple of you guys don't have a book or you are dealing with financial aid. We just can't stop.” Therefore, a key element of demonstrating cultural know-how entails recognizing that there are few exceptions in college and behaving accordingly. ${ }^{7}$

Students in particular were surprised to discover this aspect of the role, and their surprise was salient in our interviews with them. One described this expectation thusly: “[Professors are] not going to stop the lesson for you to leave. You're there for what they're talking about or you're just out.” Another said, “You need to take it seriously. ... Make sure you get everything done because teachers are not going to give you all the extensions and benefits they would give you in high school.”

Not only are community college students expected to adhere to rules and deadlines, they are also expected to adapt to various instructional styles. Professors and disciplines have varying approaches to coursework and studying, and community college

\footnotetext{
${ }^{7}$ At first blush, this finding seems to contradict the notion of fluidity within the role. But a closer read of the data indicate that fluidity and inflexibility coexist within the community college student role. The less forgiving and more inflexible nature of the role refers to the expectations and normative standards themselves - the outcomes of the role. Fluidity, on the other hand, is related to the behavioral strategies that help students meet the standards. Our data indicate that college instructors had clear, culturally based standards of behavior for students; how students reached those standards, however, was fluid since students could meet the standards in a variety of intersecting and overlapping ways. Instructors clearly wanted to feel respected and feel that students took college seriously, for example, and they generally did not make exceptions for students who do not display this respect. Strategies that students used to demonstrate respect include modes of dress, language, interpersonal behavior, work ethic, and reliability, among others.
} 
students must learn that these expectations will not change to meet their needs. The students are expected to adjust, not the instructors. One student said, "So I have to learn to work with their teaching styles to fit it into ... my learning style so that I can comprehend it better.” Note that the expected onus of change is on the student, not-as it often is in high school—on the instructor. Recognizing this difference and learning to function accordingly is a key element to exhibiting cultural know-how and enacting the college student role.

Individuals entering the community college student role are therefore faced with a significant challenge as they must contemplate how to meet role-related demands that are simultaneously diffuse and inflexible. Though the "how" of the role remains fluid - there are multiple strategies to meet expectations - the "what" is not, as deadlines, anticipated learning outcomes, and expectations are more immutable. Consequently, the role requires community college students to reflect on their needs and act accordingly. Students must develop an understanding of college culture and its ensuing behavioral expectations. Then, they must assess their own ability to adhere to those expectations. This requires students to enact the culture and behavior of college (while also maintaining their connection with their home cultural practices and languages).

Balancing multiple roles and time demands. We have already noted that community college students not only enact the community college role, but they typically also engage in other social positions as workers or as family members caring for others. These additional roles compete for their time and energy, and the stresses of these roles may conflict with the demands of the community college student role. Unlike high school students for whom it is generally assumed that their role as a student is primary, community college students may find that they must privilege the demands of other roles to the same-or even greater-degree than their student responsibilities. As a result, a fundamental expectation held of community college students is that they find ways to balance the many demands on their time associated with their multiple roles.

It is important to recognize that many of the students in our dataset defined the college experience differently from the traditional image of college that is portrayed in popular culture. Though there were a few exceptions, most students did not expect or even want an intense, college-based social life. They viewed college instrumentally- 
usually as a means to a job with sufficient wages to support a family — and were not trying to balance typical collegiate social activities with their other roles. In this way, their vision of the community college student role aligned with the expectations of faculty, who also focused on classroom- and academically-based role-related demands. Even with these smaller parameters, however, the students in our sample were expected to find ways to balance the competing demands of the community college student role and their other social roles. This was often a struggle for many students.

Our data confirm that being a modern community college student is a balancing act. Explained one student, "I work full time and have three children and a husband and a home, I can't just run over to [campus] and hope that somebody's going to be at the tutoring center.” Another student described the conflict and emphasized the need to put other roles first when she said, “Because at home I can’t hardly get anything done because my little girl wants all the attention. It's just so hard.”

Table 4 outlines various behaviors that indicate to others that community college students are successfully balancing their multiple roles. It also shows strategies used by community college students to effectively balance their multiple role responsibilities.

Table 4: Balancing Multiple Roles

\begin{tabular}{ll}
\hline \multicolumn{1}{c}{ Behaviors and attitudes } & \multicolumn{1}{c}{ Strategies } \\
\hline Make college a priority & - Take responsibility for meeting deadlines \\
& "Stick-to-it-ness" \\
$\begin{array}{l}\text { Use the fluidity of the part to their } \\
\text { advantage }\end{array}$ & - Find a schedule that works for personal circumstances \\
& - Modify obligations \\
$\begin{array}{l}\text { Communicate with instructors early } \\
\text { and often }\end{array}$ & $\begin{array}{l}\text { Earn acknowledgement of the balancing act by honest and } \\
\text { frequent communication }\end{array}$ \\
\hline
\end{tabular}

Make college a priority. A key behavior or set of behaviors expected of college students is that they make college a priority, even when other roles are important as well. It is important to recognize that this component of the role is connected to the previous one, developing cultural know-how, in that the behaviors and expectations surrounding the balancing of multiple roles are rooted in a middle-class assumption that privileges 
college-going over other responsibilities. Instructors and staff frequently expressed the notion that college should be the prominent, or at least a prominent, role in students' lives, as expressed here:

[Students] have a really hard time understanding why they're not successful when they're not putting so much extra time outside of being here on campus into their coursework. ... They feel like if they're in class that's what they need to do. But we know that there's so much more to it.

What I mean is they fail because their lifestyle prevents them. It's an obstacle. Their lifestyle, in that they have families; they have children; some of them take care of a parent; most have transportation but some might not. They have to work — they're single parents - they have to work.

Though this expectation may be culturally biased, unfair, or unrealistic, it is an assumption made by most of the staff and administration at college, and so we take it as a starting point for this component of the role. ${ }^{8}$ Moreover, although the majority of instructors we spoke with recognized the multiple roles that their students play (see second paragraph of quote directly above), this acknowledgement was almost always followed by a statement emphasizing that school and school work still needed to be completed and prioritized. Instructors often framed this as overcoming the "obstacle" of other roles; regardless of how it was stated, the message was that part of successfully being a community college student is finding a balance that privileges the student role.

Respondents frequently used phrases such as "making college a priority" or "being dedicated" to school. For instance, one instructor referred to the community college student role "as a job.” In addition, another instructor explained: "I want them to take this very seriously. I want them to take their college education very seriously and make it a priority.” Though these phrases appear vague and are hard to operationalize,

\footnotetext{
${ }^{8}$ As in the previous section, given the scope and focus of this paper, we take the cultural components of these expectations at face value, even though others (Ladson-Billings, 1995; Rosenbaum et al., 2006) have argued both in favor of and against maintaining and even explicitly teaching middle-class norms within educational institutions.
} 
further analyses indicate that instructors had specific behaviors in mind that signaled such dedication and commitment.

Instructors in our study indicated that behaviors such as completing assignments on time and meeting deadlines on a regular basis demonstrated that college was a priority. Successful community college students independently keep track of deadlines, are aware of when various tasks need to happen, adhere to those deadlines, and take responsibility for meeting them. One instructor described these behaviors and attitudes as "stick-to-it-ness." As such, they were inclined to look favorably upon students who exhibited such behaviors.

Take advantage of the fluidity of the role. Successful community college students learn to use the fluidity of the role to their advantage. The fact that time can be used flexibly can help in balancing multiple roles. For example, successful students might opt to study or visit a tutoring center between classes instead of socializing, thereby freeing up off-campus time for the demands of other roles. Because a specific mode of studying is not typically specified, successful students study in ways and at times that best meet their needs and obligations. One student described her personal strategy for completing work by saying, "I just have to put time aside. I stay here [on campus] more often than I go home; that way I don't have the distractions to do the stuff so I can succeed.”

These students also use the flexibility of the role to modify their in-school and out-of-school obligations. This may include cutting back on how many courses they are taking or designing course schedules that balance easy and hard courses in a given semester. The fact that there is flexibility in many aspects of college including course scheduling and work flow can help in this regard. An instructor described the desirability of this strategy by saying,

Someone needs to tell [students] to be realistic between balancing their goals, what they want to do, what curriculum they want to pursue, [with] working and raising a family. ... A lot of our students ... try to take full loads and raise a family and work full time, and I think that just kind of sets them up for failure in many respects. 
For many students, the key to taking advantage of the role's flexibility was having a simple, actionable plan for balancing their multiple roles. Many students discussed the benefits of having such a plan, whether for scheduling study time, seeking help, or tending to family. Such a plan gave structure to the many demands that the students faced, and it provided a systematic and thoughtful way to confront challenges when multiple roles conflicted. Explained one student,

I need to have a plan because I'm very spontaneous and I just, I go with the flow type thing. That's a good mentality but also you always need a plan. And I have realized throughout this year-and-a-half I needed a plan from the get-go because if you don't have a plan, if you're just like doing it or whatever, then you might go out of those two years with not much of what you really wanted.

Taking advantage of fluidity, particularly in order to develop a plan for balancing multiple roles, requires a highly developed ability to reflect on one's needs and act accordingly. Students need to be able to think critically about their various roles and obligations and to develop strategies that will work for their unique circumstances. They also need to have enough awareness to recognize when strategies are not working, in order to make appropriate modifications.

Communicate with instructors early and often. Another strategy used by successful community college students is to communicate with instructors honestly, early on, and often. Both students and professors indicated that, if they are inclined to be lenient in their expectations, they are more likely to do so for students who communicate with them on a regular basis. Students indicated that they desired some recognition of the balancing act they perform, particularly if they do everything in their power to make college a priority. Professors agreed, to an extent, but emphasized that the onus was on the students to ask for and earn any flexibility. One student described the way he could and should have approached his instructor when trying to balance a move and school requirements:

And I was just so busy in the move and everything that I was like, I completely forgot and I didn't really take the time out to do, you know, like I said, make school my priority either way. And that's where I messed up. And 
then when I went back with the stuff and when I went back to Miss Taylor, I was like, "Look, I’m really sorry.”

An instructor described the same process, only from the faculty point of view:

I want to meet students, maybe not halfway, maybe 80 percent. I want to meet them there, but they've got to put in the work to do that and show me that they really want it and that they're trying.

Across all elements of this component, self-reflection and meta-cognition were key. Individual students have unique circumstances, and the strategies that allow one student to meet deadlines may not work for others. Students must be able to take a critical look at their personal circumstances in order to develop strategies for success. For example, a key strategy for many students was to develop a realistic sense of what is and is not feasible, given their other role-related demands. One instructor described this as a process in which students "figure out where their balance is ... they have to figure out what they’re giving up.” Note the use of the phrase "figure out," which implies a cognitive and reflective process on the part of the student.

For some students, this figuring-out process led them to weigh various options or seek alternative ways to achieve their educational goals. This might include dropping a course, taking courses online, changing majors, or modifying their study habits. One student we met with, for example, found it difficult to keep up with her studies while enrolled full time, so she modified her academic commitments:

I was taking like 13 or 14 credits and I had an assignment here due, you know, on the same day, and I was overlapping my studying and it was really overwhelming, and so I dropped down to two classes. And that's a lot easier.

The point is that role incumbents recognized the importance of adhering to rolerelated demands, and when confronted with challenges to doing so from other areas of their lives, thought strategically about their options and made choices that modified their behaviors to allow them to balance school successfully. Engaging in this process required a high degree of self-awareness and reflection. 
Help-seeking. The final component of the college student role is engagement in help-seeking behaviors. Community college students are expected to seek out help in ways that are more proactive and self-directed than is expected of high school students or employees. They must do this in a timely manner and in ways that are more culturally delineated with a stronger sense of what they need - this is often fundamentally different from previous forms of help-seeking with which role aspirants are likely familiar. This component is obviously related to the first, academic habits, in that it supports students' academic progress. But help-seeking is a very specific kind of academic habit, and one that takes on particular importance in the community college; this component therefore appears separately in our analysis.

Respondents indicate that help-seeking in college is fundamentally different from help-seeking in high school. Unlike in secondary school and at many jobs, role alters do not approach community college students offering assistance. Instead, the students themselves are expected to funnel themselves into a preexisting structure of supports that are made available by the institution. The college offers services, and students need to find and use them on their own. Explained one student, "It's college. They do everything; they have the Learning Center, the Tutoring Center, they’ve got the library, they've got all these computer labs. I mean they offer everything. ... You have to figure it out on your own." An instructor made a similar point when saying, "I'm not going to be the Wizard of $\mathrm{Oz}$ and know everything. ... I'm just going to steer you [the student] and tell you what steps you may want to take."

The data indicate that help-seeking in the community college is a process, where students first must recognize that they need help, then must understand the possible places to get help from, and finally follow through on asking for help. Successful role incumbents learn about this process and enact it throughout their college careers. Table 5 highlights the three main parts of the process, as well as strategies used by successful community college students to engage in help-seeking behaviors. 


\begin{tabular}{lll}
\hline \multicolumn{1}{c}{ Behaviors and attitudes } & \multicolumn{1}{c}{ Strategies } \\
\hline Demonstrate awareness of need & Ask for help early \\
Gain knowledge of available resources & Anticipate areas that might become problematic in the future \\
- & $\begin{array}{l}\text { Know what resources are available } \\
\text { Know when to use resources, how to do so appropriately, and } \\
\text { which ones to use }\end{array}$ \\
Develop a sense of agency & $\begin{array}{l}\text { Take the initiative to seek out help } \\
\text { Ask for assistance rather than waiting for it to be offered } \\
\end{array}$ \\
\hline
\end{tabular}

Develop an awareness of need. Before they can ask for help, community college students must recognize that they need assistance. Since others are unlikely to approach them and offer help, students must diagnose their needs on their own. For example, they need to realize that they will need help in a certain subject, or that they will need guidance in planning their schedule for the following semester. One instructor noted the need for student awareness by saying, "If you're not good at math and you need help and you're struggling, you need to avail yourself" of available services. Another college's tutoring center made this demand even more explicit, requiring students seeking assistance to articulate a specific problem to be solved or goal to be accomplished prior to each tutoring session.

Ideally, students must recognize that they might need help before the need becomes acute. Said one instructor, "We have students who are coming in the last few weeks and they say they don't understand anything. Well, there's no way we can bring them up to speed." Another expressed frustration that students often don't seek out advisors until they are failing: "Students don't have to see their advisor unless they have a block on there. They have a block because their average has dropped below $\mathrm{C}$, then in order to register they need to see someone.”

Gain knowledge about available resources. Community college students are also expected to have a working knowledge of available resources, including college support services, supportive staff and faculty, and sources of information. This means that they are expected to know what resources are at their disposal, when those resources are 
available, what those resources can provide, and how to use them appropriately. An instructor noted that many new community college students do not have this knowledge, saying, "And so I guess that's the problem. There is a group that [does] not ask the questions that need to be asked, who don't even know that they need to be doing that.”

Another instructor described the expectation that community college students know what resources exist and how to avail themselves of their help more succinctly: "Whether they take advantage of [available services] is their personal decision." A student described this role-related expectation from the student perspective, saying "the important thing [in asking for help] is a student has to do their part.” This student noted that she was not having success in community college because she was not "doing her part.”

Another key element of this expectation is that community college students are able to navigate multiple resources. Most community colleges have myriad support services at students' disposal, from advising and tutoring to informal interactions with faculty. The expectation is that students will not only know about all of these resources and when to use them, but also which resource to use for any given problem. As such, role alters expect community college students to be reflective enough to diagnose and solve problems on their own. They are also expected to develop skills that will enable them to self-advise or independently develop solutions to various educational and bureaucratic obstacles. An instructor explained: "We look at it as making sure that you understand what's here and get you jump-started. At the same time, our goal is to make sure that you're able to function yourself."

Develop a sense of agency. Finally, once community college students have identified both a problem and places that might assist them in solving it, they are expected to take the initiative to seek out that help. We refer to this as having a sense of agency, in that role incumbents are expected to take action for themselves rather than wait for others to do so for them. Exhibiting help-seeking agency is a behavioral hallmark of the community college student role. Role alters view students' attempts to get help for themselves as a key indicator that they are committed to the role and have learned how to enact it successfully. Failure to demonstrate this type of behavior, on the other hand, is likely to lead to negative perceptions. 
One instructor summed up this expectation by saying, “And you have to keep telling them, "You are a college student now, I'm not going to outline everything for you. You've got to read [materials about campus policies, procedures, and services], you've got to know where you stand." Note that she uses the words "college student," explicitly linking the behaviors in this quote to individuals' status (or lack of status) in the role. Her words emphasize the need for students themselves to take action, by reading and understanding what needs to be done.

Agency is seen in a variety of behaviors. Students demonstrate agency when they seek out and demand help when they need it—in essence, becoming their own advocates. Study participants were very clear that such self-advocacy was a key element of the community college student role, and that those individuals who are unable or unwilling to proactively seek out help were unlikely to be successful. One instructor summed up this sentiment when saying,

Students who do not seek out advising, students who do not ask questions or who do not have self-advocacy skills to go, “something doesn't look right here," may truly not get the help that they need until they apply for graduation and receive that letter saying, "Oops, you still have these four requirements.”

Clearly, reflection and self-awareness are necessary in all three phases of the help-seeking process. Students cannot recognize that they need help if they are unable to assess their strengths and weaknesses, and they are unlikely to be able to identify the correct type of help or service without the ability to reflect on their own needs. Students need to have enough self-knowledge to understand what they need and how to get it. It is worth noting that self-reflection and help-seeking are not the same thing. For example, a student can reflect on their learning without translating that reflection into help-seeking, while others may seek out help without first thinking about what type of assistance they really need. Still other students may decide, upon self-assessment, that they do not actually need to seek out additional assistance.

It is important to recognize - though many of our respondents did not seem to do this - that the types of proactive help-seeking described here constitute another culturally constructed expectation. Asking for help, for some students, is anxiety-provoking. For 
other students, particularly those for whom college is unfamiliar and who may see themselves as not really belonging in postsecondary education, engaging in help-seeking behavior may be challenging or even identity-threatening (Gardenhire-Crooks, Collado, Martin, \& Castro, 2010; Cox, 2009).

\section{Conclusions and Recommendations}

This paper used interview data from students, faculty, and staff at three Virginia community colleges to refine, extend, and clarify the role of a community college student. We did this because much of the existing research on the high school-to-college transition and on college preparation focuses on academic preparation, traditional fouryear students, or both. Researchers have been generally inattentive to the non-academic components of college preparation, and have been particularly silent when it comes to what those expectations are in non-residential, non-four-year institutions.

Analyzing data from over 170 interview transcripts, we identified four distinct components of the role: academic habits, cultural know-how, balancing multiple roles, and help-seeking. We also found that the community college student role differs from other roles with which students might be familiar, such as those of a worker, family member, or high school student, because of both its fluidity and the greater degree to which self-awareness and reflection is necessary for successful role enactment. As such, the community college role is a challenging one for students to understand and enact. The overarching elements and specific components identified here can serve as a basis for improved student preparation for college. Practitioners can use these findings in a variety of ways to help potential and new community college students better understand what will be expected of them during their community college experience.

Working with students to explain the non-academic demands to which community college students are held is a key college preparation and success strategy, as our findings indicate that while the fluidity and flexibility of the role can be beneficial, these aspects can also leave room for confusion and misinterpretation. Without clear signposts to guide them, community college students are likely to find it challenging to know how to enact role-related expectations. They may also have a hard time recognizing whether or not 
they are meeting the demands of the community college student role. Finally, because the community college student role is considerably different from the other roles they might inhabit, they have fewer cognitive resources to rely on as they develop their own interpretations of and integration into the college student role.

In order to prepare students for the community college student role, practitioners need recognize that successful role enactment entails two things: (1) understanding the normative expectations of the role and (2) having the cognitive repertoires that allow for normatively appropriate behaviors. This means that students need to be told that there are distinct expectations to which they will be held in the community college, given examples of those expectations, and shown (or, ideally, allowed to practice) strategies for meeting these expectations. It also means that new and potential community college students need to be given the opportunity to develop the reflective and metacognitive skills required to select strategies and behaviors for their specific role-related circumstances.

The tables presented throughout this paper provide an approach to helping students understand the normative role of a community college student. Presenting the tables, or documents based on them, to students might help students recognize that such expectations exist and might provide them with a set of strategies to use. This could be carried out in college orientation or College 101 courses, or even in meetings with college applicants or in high schools. Instructors can also use these tables to construct exercises in which their students are given the opportunity to practice these strategiesasking them to construct multiple ways to study for an exam, for example.

Whether via the tables or another strategy, scaffolding students' learning so that they are introduced to the expectations of the community college student role in a developmental manner is a key college readiness strategy. This is particularly true for students who are from cultures other than the middle-class, White culture upon which collegiate norms are based. Meeting students where they are, in terms of norms, expectations, and understandings, and helping them generate more detailed and actionable understandings of community college expectations can help them become comfortable with and successful in community college while maintaining cultural pluralism. 
It is essential that any attempt to communicate the norms of the community college student role occur outside of high school. Secondary schooling is an opportune place to provide such information, of course, but since many community college students enter postsecondary education from outside of high school, college readiness efforts cannot focus solely on that institution. Instead, community colleges must find ways to communicate these expectations to a broader population. This might include leveraging adult basic education programs, worker retraining programs, or even popular media. And because all new community college students encounter the classroom, finding ways to communicate role-related norms and expectations early and often in students' college courses is essential. Community college instructors, if given the language to articulate their expectations clearly, can and should work to incorporate opportunities for expressing their expectations to students from the outset of their courses.

In addition, it is imperative that students develop the appropriate reflective and metacognitive skills, which may be harder to achieve as such skills require students to cultivate new ways of thinking. Community college students are expected to become selfregulated learners who are able to assess their needs and progress, think critically about their options, and act in ways best suited to their personal circumstances. Developing such skills occurs over time, and students need ample opportunity to practice and build their skills. Research suggests that it is possible to teach students these skills (Zimmerman et al., 2011) and that doing so can improve student outcomes (Dignath \& Büettner, 2008).

Providing students with opportunities to practice reflecting on their educational progress and problem-solve in relation to their academic lives is critical in preparing them for the role of a community college student. As with communicating the norms of the role, such practice needs to occur during and outside of high school. Helping new community college students become reflective individuals needs to be incorporated into the first-year community college curriculum. Instructors should help their new students develop the metacognitive skills necessary for future college success. Activities such as student success courses and one-on-one guidance sessions can also serve as venues for developing and practicing these skills, but given scarce resources, a key location for sustained metacognitive practice is the academic classroom itself. A range of 
instructional strategies, including contextualized instruction, conceptual learning, and collaborative practice, can encourage the development of metacognitive skills, including self-awareness and reflection (Flavell, 1979; Davidson et al., 1994; Perin \& Hare, 2010).

The data presented in this paper are used to provide a clear, actionable set of expectations to which community college students are held and the strategies by which successful community college students meet these expectations. Currently, these expectations are held by college instructors but they are rarely clearly articulated to aspiring and new community college students. If they are communicated at all, they are generally referred to in vague and incomplete language—-leaving students with little real guidance about the expectations to which they are held.

The clearly defined expectations and strategies presented in this paper may therefore provide an important foundation for improving student readiness at community college. Finding ways to communicate these expectations to students-clearly, early on, and in ways that they can understand and use-is a key next step. Doing so will not be easy, particularly for the many students who enter community college from outside of the education system, but the effort could be a way to alleviate some of the frustration that students experience and could potentially move the needle on student success. Community college leaders and practitioners should consider finding ways to accomplish this task. 


\section{References}

Attinasi, L. C. (1989). Getting in: Mexican-Americans’ perceptions of university attendance and the implications for freshman year persistence. Journal of Higher Education, 60(3), 247-277.

Aud, S., Hussar, W., Johnson, F., Kena, G., Roth, E., Manning, E., . . Zhang, J. (2012). The condition of education 2012 (NCES 2012-045). Washington, DC: U.S. Department of Education, National Center for Education Statistics.

Bailey, T., Jeong, D. W., \& Cho, S. W. (2010). Referral, enrollment, and completion in developmental education sequences in community colleges. Economics of Education Review, 29, 255-270.

Bernard, H. R. (2002). Research methods in anthropology: Qualitative and quantitative approaches (3rd ed.). Walnut Creek, CA: Altamira Press.

Blumer, H. (1969). Symbolic interactionism. Englewood Cliffs, NJ: Prentice Hall.

Bill \& Melinda Gates Foundation. (n.d.). Why college completion? Retrieved from http://www.gatesfoundation.org/postsecondaryeducation/Pages/why-collegecompletion.aspx

Byrd, K. L., \& Macdonald, G. (2005). Defining college readiness from the inside out: First-generation college student perspectives. Community College Review, 33(1), 22-37.

Carver, C. S., \& Scheier, M. F. (1981). Attention and self-regulation: A control theory approach to human behavior. New York, NY: Springer-Verlag.

Cho, S. W., \& Karp, M. M. (2012). Student success courses and educational outcomes at Virginia community colleges (CCRC Working Paper No. 40). New York, NY: Columbia University, Teachers College, Community College Research Center.

Choy, S. (2002). Nontraditional undergraduates (NCES 2002-012). Washington, DC: U.S. Department of Education, National Center for Education Statistics. Retrieved from http://nces.ed.gov/programs/coe/analysis/2002a-sa01.asp

Collier, P. J., \& Morgan, D. L. (2008). “Is that paper really due today?” Differences in first-generation and traditional college students' understandings of faculty expectations. Higher Education, 55, 425-446.

Conley, D. T. (2005). College knowledge: What it really takes for students to succeed and what we can do to get them ready. San Francisco, CA: Jossey-Bass.

Conley, D. T. (2007a). The challenge of college readiness. Educational Leadership, 64(7), 23-29. 
Conley, D. T. (2007b). Redefining college readiness (Volume 3). Eugene, OR: Educational Policy Improvement Center.

Conley, D. T. (2010). College and career ready: Helping all students succeed beyond high school. San Francisco, CA: Jossey-Bass.

Cox, R. D. (2009). The college fear factor: How students and professors misunderstand one another. Cambridge, MA: Harvard University Press.

Davidson, J. E., Deuser, R., \& Sternberg, R. J. (1994).The role of metacognition in problem solving. In J. Metcalfe \& A. Shimamura (Eds.), Metacognition: Knowing about knowing (pp. 207-226). Cambridge, MA: MIT Press.

Dickie, L. O., \& Farrell, J. E. (1991). The transition from high school to college: An impedance mismatch? The Physics Teacher, 29(7), 440-445.

Dignath, C., \& Büettner, G. (2008). Components of fostering self-regulated learning among students: A meta-analysis on intervention studies at primary and secondary school level. Metacognition and Learning, 3(3), 231-264.

Duckworth, K., Akerman, R., MacGregor, A., Salter, E., \& Vorhaus, J. (2009). Selfregulated learning: A literature review (Research Report No. 33). London, UK: University of London, Institute of Education, Centre for Research on the Wider Benefits of Learning Research.

Ebaguh, H. R. F. (1988). Becoming an ex: The process of role exit. Chicago, IL: University of Chicago Press.

Flavell, J. H. (1979). Metacognition and cognitive monitoring: A new area of cognitivedevelopmental inquiry. American Psychologist, 34(10), 906-911.

Gardenhire-Crooks, A., Collado, H., Martin, K., \& Castro, A. (2010). Terms of engagement: Men of color discuss their experiences in community college. New York, NY: MDRC.

Goffman, E. (1961). Encounters: Two studies in the sociology of interaction. Indianapolis, IN: Bobbs-Merrill.

Hurtado, S., \& Carter, D. F. (1997).Effects of college transition and perceptions of the campus racial climate on Latino college students' sense of belonging. Sociology of Education, 70(4), 324-345.

Ibarra, H. (1999). Provisional selves: Experimenting with image and identity in professional adaptation. Administrative Science Quarterly, 44(4), 764-791.

Jenkins, D., Jaggars, S. S., Roksa, J., Zeidenberg, M., \& Cho, S. W. (2009). Strategies for promoting gatekeeper course success among students needing remediation: Research report for the Virginia community college system (Full-length technical 
report). New York, NY: Columbia University, Teachers College, Community College Research Center.

Karp, M. M., Bickerstaff, S., Rucks-Ahidiana, Z., Bork, R. H., Barragan, M., \& Edgecombe, N. (2012). College 101 courses for application and student success (CCRC Paper). New York, NY: Columbia University, Teachers College, Community College Research Center. Manuscript in preparation.

Karp, M. M. (2011). Toward a new understanding of non-academic support: Four mechanisms encouraging positive student outcomes in the community college (CCRC Working Paper No. 28, Assessment of Evidence Series). New York, NY: Columbia University, Teachers College, Community College Research Center. .

Karp, M. M. (2006). Facing the future: Identity development among College Now students (Doctoral dissertation). Available from ProQuest Dissertation and Theses database. (AAT 3199561)

Lacy, K. R. (2007). Blue-chip black: Race, class, and status in the new black middle class. Berkeley, CA: University of California Press.

Ladson-Billings, G. (1995). Toward a theory of culturally relevant pedagogy. American Educational Research Journal, 32, 465-491.

Le Compte, M. D., \& Preissle, J. (1993). Ethnography and qualitative design in educational research (2nd ed.) San Diego, CA: Academic Press.

Lumina Foundation for Education. (2009). Lumina Foundation's strategic plan: Goal 2025. Indianapolis, IN: Author. Retrieved from http://www.luminafoundation.org/wpcontent/uploads/2011/02/Lumina_Strategic_Plan.pdf

Merton, R. K. (1957). Social theory and social structure (Revised ed.). London, UK: The Free Press of Glencoe.

Oleson, V. L., \& Whittaker, E. W. (1968). The silent dialogue: A study in the social psychology of professional socialization. San Francisco, CA: Jossey-Bass.

Paris, D. (2012). Culturally sustaining pedagogy: A needed change in stance, terminology, and practice. Educational Researcher, 41(3), 93-97.

Perin, D., \& Hare, R. (2010). A contextualized reading-writing intervention for community college students (CCRC Brief No. 44). New York, NY: Columbia University, Teachers College, Community College Research Center.

Provasnik, S., \& Planty, M. (2008). Community colleges: Special supplement to The Condition of Education 2008 (NCES 2008-033). Washington, DC: U.S. Department of Education, Institute of Education Sciences, National Center for Education Statistics. 
Ragin, C. C. (1994). Constructing social research: The unity and disunity of method. Thousand Oaks, CA: Pine Forge Press.

Rendon, L. I., Jalomo, R. E., \& Nora, A. (2000). Theoretical considerations in the study of minority student retention in higher education. In J. M. Braxton (Ed.), Reworking the student departure puzzle (pp. 127-156). Nashville, TN: Vanderbilt University Press.

Roderick, M., Nagaoka, J., \& Coca, V. (2009). College readiness for all: The challenge for urban high schools. The Future of Children, 19(1), 185-210.

Roderick, M., Nagaoka, J., Coca, V., Moeller, E., \& (with Roddie, K., Gilliam, J., \& Patton, D). (2008). From high school to the future: Potholes on the road to college. Chicago, IL: University of Chicago, Consortium on Chicago School Research.

Rosenbaum, J. E., Deil-Amen, R., \& Person, A. E. (2006). After admission: From college access to college success. New York, NY: The Russell Sage Foundation.

Rosenbaum, J. E., Stephan, J. L., \& Rosenbaum, J. E. (2010). Beyond one-size-fits-all college dreams: Alternative pathways to desirable careers. American Educator 34(3), 2-13.

Shields, N. (2002). Anticipatory socialization, adjustment to university life, and perceived stress: Generational and sibling effects. Social Psychology of Education, 5, 365-392.

Simpson, I. H. (1979). From student to nurse: A longitudinal study of socialization. Cambridge, United Kingdom: Cambridge University Press.

Tierney, W. G. (1999). Models of minority college-going and retention: Cultural integrity versus cultural suicide. Journal of Negro Education, 68(1), 80-91.

Turner, R. H. (1990). Role change. Annual Review of Sociology, 16, 87-110.

Venezia, A., Bracco, K. R., \& Nodine, T. (2010). One-shot deal? Students’ perceptions of assessment and course placement in California's community colleges. San Francisco, CA: WestEd. Retrieved from http://www.wested.org/online_pubs/OneShotDeal.pdf

Venezia, A., Kirst, M. W., \& Antonio, A. L. (2003). Betraying the college dream: How disconnected K-12 and postsecondary education systems undermine student aspirations (Final Report of the Bridge Project). Stanford, CA: Stanford Institute for Higher Education Research.

The White House, Office of the Press Secretary. (2009, February 24). Presidential address to joint session of Congress. Retrieved from 
http://www.whitehouse.gov/the_press_office/Remarks-of-President-BarackObama-Address-to-Joint-Session-of-Congress/

Zimmerman, B. J. (1990). Self-regulated learning and academic achievement: An overview. Educational Psychologist, 25(1), 3-17.

Zimmerman, B. J. (2001). Theories of self-regulated learning and academic achievement: An overview and analysis. In B. J. Zimmerman \& D. H. Schunk (Eds.), Selfregulated learning and academic achievement: Theoretical perspectives (pp. 138). Mahwah, NJ: Lawrence Erlbaum Associates.

Zimmerman, B. J., Moylan, A., Hudesman, J., White, N., \& Flugman, B. (2011). Enhancing self-refection and mathematics achievement of at-risk urban technical college students. Psychological Test and Assessment Modeling, 53(1), 141-160. 